\title{
High-fat diet induces emergence of brown-like adipocytes in white adipose tissue of spontaneously hypertensive rats
}

\author{
Silvie Hojna ${ }^{1,3}$, Melissa D Jordan ${ }^{1,3}$, Helen Kollias ${ }^{2}$ and Zdenka Pausova ${ }^{1,2}$ \\ Obesity has a profound adverse impact on health. In this study, we present evidence for high-fat diet (HFD)-induced emergence \\ of brown-like adipocytes in white adipose tissue (WAT) of the spontaneously hypertensive rat (SHR). We studied adult males fed \\ a HFD or normal diet (ND) for 12 weeks. At the end of the 12-week dietary intervention, HFD compared with ND rats showed \\ significantly higher whole-body energy expenditure. HFD vs. ND rats also showed higher expression of genes involved in fatty \\ acid oxidation, mitochondrial biogenesis and brown fat adipogenesis, as well as augmented mitochondrial mass in WAT but not \\ in the liver or skeletal muscle. Consistent with the molecular changes, in HFD but not in ND rats, histological and \\ immunohistochemistry-based analyses of WAT demonstrated the presence of small multilocular cells staining positively for \\ uncoupling protein 1 , indicating the emergence of brown-like adipocytes in WAT. Our results suggest that SHR may have the \\ capacity to increase energy expenditure in response to a chronic HFD that may be linked to the emergence of brown-like \\ adipocytes in WAT. Thus, the SHR may be an important genetic model to uncover novel mechanisms of resistance to dietary \\ obesity. \\ Hypertension Research (2012) 35, 279-286; doi:10.1038/hr.2011.188; published online 1 December 2011
}

Keywords: brown-like adipocytes; energy expenditure; high-fat diet; obesity; white adipose tissue and adipogenesis

\section{INTRODUCTION}

A high prevalence of obesity, which has become a characteristic feature of most industrialized countries, is associated with a profound adverse impact on population health, including the development of cardiovascular disease, a leading cause of morbidity and mortality in industrialized countries. ${ }^{1}$

Obesity is defined by the expansion of white adipose tissue (WAT), but recent evidence suggests that the adult human body also contains functionally distinct, brown adipose tissue. ${ }^{2-8}$ In contrast to WAT, which has a primary role in energy storage, brown adipose tissue specializes in energy dissipation as heat (Cannon and Nedergaard ${ }^{9}$ ). This thermogenic property of brown fat results from its high content of mitochondria, cell organelles where energy dissipation occurs. ${ }^{10}$ Uniquely in brown fat, mitochondria express uncoupling protein 1 (UCP1), which is a protein that resides in the inner mitochondrial membrane and facilitates a proton leak across the membrane, so that energy generated from oxidation of macronutrients, such as fat, is dissipated as heat rather than preserved through typical ATP production. ${ }^{11}$ Although white and brown adipose tissues generally occupy distinct locations within the body, some white fat depots may contain brown-like adipocytes. ${ }^{12,13}$ Importantly, the presence of these brown- like adipocytes in WAT, even in very small quantities, is associated with a significant reduction in whole-body adiposity. ${ }^{14}$ Despite the recent advances in understanding brown fat adipogenesis, ${ }^{15-18}$ the molecular mechanisms of brown fat emergence in traditional WAT have yet to be elucidated. A complex network of transcription factors that includes peroxisome proliferator-activated receptor- $\gamma$ coactivator$1 \alpha$ (PGC- $1 \alpha$ ) controls brown fat adipogenesis. PGC- $1 \alpha$ regulates mitochondrial biogenesis and fat oxidation by coordinating expression of both mitochondrial genome- and nuclear genome-encoded genes involved in these processes, and it also induces expression of the brown fat-defining UCP1. ${ }^{19}$

Previous research suggests that (i) brown fat emergence in WAT can be induced by sympathetic $\beta$-adrenergic stimulation ${ }^{20-22}$ and (ii) dietary fat can increase sympathetic outflow from the central nervous system to the periphery. ${ }^{23}$ Given these observations, we hypothesized that the spontaneously hypertensive rat (SHR) may be a genetic strain that is susceptible to the emergence of brown fat in WAT in response to a high-fat diet (HFD), as it is characterized by high sympathetic outflow to the periphery, including to WAT, ${ }^{24-27}$ and shows augmentations in sympathetic activity (indicated indirectly by an augmentation in heart rate $)^{28}$ and expression of genes involved in fat burning in WAT in

\footnotetext{
${ }^{1}$ Brain and Body Centre, University of Nottingham, Nottingham, UK and ${ }^{2}$ The Hospital for Sick Children, Toronto, Canada

${ }^{3}$ These authors contributed equally to this work.

Correspondence: Dr Z Pausova, Scientist, The Hospital for Sick Children, Associate Professor of Physiology and Nutritional Sciences, University of Toronto, Toronto, Canada M5G 1 X8. E-mail: zdenka.pausova@sickkids.ca

Received 30 May 2011; revised 29 July 2011; accepted 17 August 2011; published online 1 December 2011
} 
response to a chronic HFD. ${ }^{29}$ SHR compared with Wistar Kyoto rats, for example, also gain less body weight in response to a chronic HFD. ${ }^{30-33}$ To test our hypothesis, we exposed adult SHR to either a HFD or normal diet (ND) for 12 weeks. Before and during the dietary intervention, we assessed adiposity and measured 24-hour profiles of whole-body energy expenditure and energy intake. At the end of the intervention, we examined molecular and cellular pathways involved in fat burning and energy expenditure in WAT. The latter resulted in observing the emergence of brown fat in WAT in HFD but not in ND rats.

\section{METHODS}

\section{Animals}

Male SHR originating from a colony of the Czech Academy of Sciences, Prague, Czech Republic (SHR/Ola) and bred at the University of Nottingham, Nottingham, UK were studied.

\section{Experimental protocol}

At 16 weeks of age, whole-body energy expenditure (as assessed by indirect calorimetry) and food intake were monitored with the Comprehensive Laboratory Animal Monitoring System (CLAMS, Columbus Instruments, Columbus, OH, USA) for two consecutive 24-hour periods. Following these initial (week 0) measurements, rats either remained on a ND $(n=6 ; 2018$ Teklad, Harlan, Loughborough, UK; metabolisable energy: $3.3 \mathrm{kcal} \mathrm{g}^{-1} ; 6.2 \%$ fat) or were placed on a HFD $(n=8 ;$ F3282, Bio-Serv, Frenchtown, NJ, USA; metabolisable energy: $5.3 \mathrm{kcal} \mathrm{g}^{-1} ; 35.5 \%$ fat) for 12 weeks. The relative content of saturated, monounsaturated and polyunsaturated fatty acids was 16, 23 and $61 \%$ of total fat in ND, and it was 40,23 and $17 \%$ of total fat in HFD. The higher content of fat in HFD than ND was driven mainly by excess of palmitic $\left(\mathrm{C}_{16}\right)$ and oleic $\left(\mathrm{C}_{18: 1}\right)$ fatty acids in the former. The CLAMS measurements performed initially (week 0 ) were repeated in the middle (week 6) and at the end (week 12) of the 12-week dietary intervention. Animals were housed singly under standard conditions (ambient temperature $23 \pm 1{ }^{\circ} \mathrm{C}, 12 \mathrm{~h}$ light-dark cycle; dark phase 1900-0700 hours) with free access to water and food. Body weight was monitored weekly throughout the intervention. At the end of the 12-week intervention, animals were humanely killed by dislocation of the neck after regular overnight feeding between 0900 and 1200 hours. Their retroperitoneal fat and epididymal fat pads, liver and soleus muscle were carefully dissected, weighed, snap-frozen in dry ice-chilled isopentane and then stored at $-80^{\circ} \mathrm{C}$ until further processing. All procedures and the experimental protocol were approved by the UK Home Office (PL 40/2881).

\section{Comprehensive Laboratory Animal Monitoring System}

The CLAMS (Columbus Instruments) is a computer-driven system that includes an open-circuit Oxymax calorimeter consisting of eight chambers in which rats are housed individually. The gas sensor was calibrated before each measurement. The flow rate of air through the chambers was adjusted to $21 \mathrm{~min}^{-1}$ and an extracted outflow to $0.41 \mathrm{~min}^{-1}$. The ambient air (input air for the chambers) and the expired air were sequentially analyzed for $\mathrm{CO}_{2}$ and $\mathrm{O}_{2}$ with a gas analyzer every $13 \mathrm{~min}$. Heat production, which is an index of whole-body energy expenditure, was calculated from $\mathrm{O}_{2}$ consumption $\left(\mathrm{VO}_{2}\right)$ and $\mathrm{CO}_{2}$ production $\left(\mathrm{VCO}_{2}\right)$ as follows: heat $\left(\mathrm{kcal} \mathrm{kg}^{-1} \mathrm{~h}^{-1}\right)=(3.815+1.232 \times$ $\left.\left(\mathrm{VCO}_{2} / \mathrm{VO}_{2}\right)\right) \times \mathrm{VO}_{2}\left(\mathrm{ml} \mathrm{kg}^{-1} \mathrm{~h}^{-1}\right.$; Columbus Instruments). ${ }^{34,35}$ In addition, cumulative weight of consumed food was monitored continuously and recorded every $13 \mathrm{~min}$. All animals were monitored for at least two 24-hour periods, with the first one used for acclimatization to the chambers and the second for data analysis.

\section{Quantitative reverse-transcription PCR (qRT-PCR)}

Total RNA from retroperitoneal fat, epididymal fat, liver and soleus muscle was isolated using TRI Reagent (Sigma-Aldrich, St Louis, MO, USA) and $1 \mu \mathrm{g}$ was treated with the RQ1 RNase-Free DNase kit (Promega, Madison, WI, USA) to remove any contaminating traces of DNA. Following this, cDNA synthesis was performed using M-MLV Reverse Transcriptase and random primers (Promega) according to the manufacturer's instructions. For all genes (Supplementary Table S1), standard curves were produced from serial dilutions of a pooled sample of cDNA from all individual samples within each tissue, and PCR amplification efficiencies were calculated from the standard curves using the equation $E=10^{[-1 / \text { slope }]}$. PCR efficiencies were all within the accepted range of 90-100\%. qRT-PCR reactions were performed using the SensiMix Plus SYBR Green PCR kit (Quantace, London, UK) on a Rotor Gene 3000 cycler (Corbett Research, Sydney, Australia). Reactions were run in triplicate, each tube containing $2.5 \mu \mathrm{l}$ of cDNA template, $0.75 \mu \mathrm{l}$ of each primer $(10 \mu \mathrm{M}), 12.5 \mu \mathrm{l}$ of SYBR mix and $8.5 \mu$ lof RNase-free water. Cycling conditions included an initial hold of $10 \mathrm{~min}$ at $95^{\circ} \mathrm{C}$, followed by 40 cycles of $95^{\circ} \mathrm{C}$ for $15 \mathrm{~s}, 60-63^{\circ} \mathrm{C}$ for $30 \mathrm{~s}$ and $72^{\circ} \mathrm{C}$ for $30 \mathrm{~s}$. A melt-curve analysis was performed at the end of each run to determine the amplification specificity. Gene-expression levels were determined using relative quantification ${ }^{36}$ with phosphoglycerate kinase 1 $(P g k 1)$ as a reference gene. ${ }^{37}$

\section{Quantification of mitochondrial DNA copy number}

Total DNA (including both nuclear DNA and mitochondrial DNA (mtDNA)) was isolated from retroperitoneal fat, liver and soleus muscle using the DNeasy Blood and Tissue Kit (Qiagen, West Sussex, UK). For the DNA extraction, retroperitoneal fat and soleus muscle samples were ground to powder in liquid nitrogen and then incubated with proteinase $\mathrm{K}$ for $2 \mathrm{~h}$, whereas the liver samples were incubated with proteinase $\mathrm{K}$ overnight without prior homogenization. During the extraction protocol, samples were treated with RNase (Roche Applied Science, Indianapolis, IN, USA) to remove any possible traces of contaminating RNA. Quantification of total DNA was performed with a Nanodrop 1000 spectrophotometer (Thermo Scientific, Waltham, MA, USA). Copy number of mtDNA was assessed with quantitative PCR (qPCR) and expressed as the ratio of mtDNA to nuclear DNA, which is thought to reflect the tissue concentration of the mtDNA per cell. ${ }^{38}$ To quantify mtDNA, we amplified fragments from two mitochondrial genes, cytochrome b $(C y t b)$ and cytochrome c oxidase, subunit I (Coxl). To quantify nuclear DNA, we amplified a fragment from the nuclear $18 \mathrm{~S}$ ribosomal RNA gene (18S). qPCR reactions were prepared and run as described above. Primer sequences are presented in Supplementary Table S1.

\section{UCP-1 protein in WAT: western blot analysis}

Total protein was extracted from frozen and powdered (as described above) retroperitoneal fat pads using tissue extraction reagent I (Invitrogen, Camarillo, CA, USA) containing protease inhibitor cocktail (Sigma-Aldrich). Protein concentrations were determined by bicinchoninic acid BCA microplate assay (Pierce, Rockford, IL, USA) and equivalent amounts of sample protein extracts $(10 \mu \mathrm{g})$ were electrophoretically resolved by sodium dodecyl sulfate-polyacrylamide gel electrophoresis on a $12 \%$ tris-glycine gel (Bio-Rad, Hercules, CA, USA) along with $0.5 \mu \mathrm{g}$ of protein extract from interscapular brown fat, a positive control for UCP1. After electrophoretic transfer to an Immun-blot polyvinyllidene difluoride (PVDF) membrane (Bio-Rad), the membrane was stained with Ponsceau S (Sigma-Aldrich) to ensure equal protein loading. Immunoblotting included an incubation in blocking buffer ( $5 \% \mathrm{wt} / \mathrm{vol}$ milk in tris-buffered saline with $0.1 \%$ Tween-20) at room temperature for $1 \mathrm{~h}$, followed by an incubation in anti-UCP1 polyclonal antibody (1:2000, U6382, SigmaAldrich; diluted in $5 \%$ bovine serum albumin in tris-buffered saline with $0.1 \%$ Tween-20) with gentle agitation at $4{ }^{\circ} \mathrm{C}$ for $16 \mathrm{~h}$ and an incubation in antirabbit horseradish peroxidase-conjugate secondary antibody (Millipore, Chemicon International, Billerica, MA, USA; diluted to 1:5000 in blocking buffer) with gentle agitation at room temperature for $1 \mathrm{~h}$. The membrane was then visualized using enhanced chemiluminescence reagent (Bio-Rad) and BioMax Light film (Kodak, Carestream Health, Rochester, NY, USA).

\section{Morphology of brown fat in WAT and UCP1 immunohistochemistry}

Retroperitoneal fat pads were fixed in $3.7 \%$. formaldehyde, embedded in paraffin and sectioned at $5 \mu \mathrm{m}$. Sections were stained with hematoxylinphloxin — saffron and brown fat morphology was examined with light microscopy (Eclipse, TE-2000-S, Nikon UK Limited, Kingston upon Thames, UK) under $\times 20$ and $\times 40$ magnifications. Additional, consecutive sections were immunostained with rabbit anti-UCP1 (1:500, U6382, Sigma-Aldrich) using the VECTASTAIN Elite ABC Kit and the VECTOR DAB Substrate Kit for 
Peroxidase (Vector Laboratories, Burlingame, CA, USA) and again examined with light microscopy (Eclipse, TE-2000-S, Nikon UK Limited) under $\times 20$ and $\times 40$ magnifications. Negative controls were performed with the same protocol, with the primary antibody being omitted.

\section{Statistical analyses}

Energy expenditure at weeks 0, 6 and 12 was analyzed with two-way analysis of variance with diet (ND vs. HFD) and time (light period $v s$. dark period) as main factors. Body and tissue weights, gene expression and mtDNA copy number at the time of killing were analyzed with Student's $t$-test to assess the differences between ND and HFD animals. If the data was not normally distributed (Ucp1 expression), a non-parametric Wilcoxon's test was used. All data are presented as mean \pm s.e.m. Statistical analyses were carried out with JMP (version 5.1.2, SAS Institute, Cary, NC, USA).

\section{RESULTS}

Effect of chronic HFD on energy expenditure

The basic characteristics of the studied animals are provided in Table 1. Energy expenditure, assessed with indirect calorimetry (Figure 1), did not differ between HFD and ND groups at weeks 0 and 6 . However, at week 12, it was significantly higher in HFD than ND rats, with the difference being apparent mainly during the active, dark period (diet $x$ time interaction: $P=0.04$; Figure 1 ). Cumulative energy

Table 1 Body and tissue weights at the end of the 12-week dietary intervention

\begin{tabular}{lccc}
\hline Body and tissue weights & ND (n=6) & HFD ( $\mathrm{n}=8)$ & P-value \\
\hline Initial body weight (IBW, g) & $312.0 \pm 7.5$ & $320.5 \pm 6.5$ & 0.4 \\
Body-weight gain (g) & $94.6 \pm 5.4$ & $108.8 \pm 7.3$ & 0.2 \\
Retroperitoneal fat weight (g) & $3.66 \pm 0.3$ & $6.16 \pm 0.5$ & 0.002 \\
Retroperitoneal fat weight (g) & $1.17 \pm 0.1$ & $1.92 \pm 0.14$ & 0.002 \\
per 100 g IBW & & & \\
Epididymal fat weight (g) & $3.8 \pm 0.1$ & $4.7 \pm 0.3$ & 0.02 \\
Epididymal fat weight (g) & $1.22 \pm 0.03$ & $1.48 \pm 0.09$ & 0.04 \\
per 100 g IBW & & & \\
Liver weight (g) & $14.3 \pm 0.3$ & $14.6 \pm 0.4$ & 0.6 \\
Liver weight (g) per 100 g IBW & $4.59 \pm 0.07$ & $4.56 \pm 0.1$ & 0.9 \\
Soleus muscle weight (g) & $0.27 \pm 0.009$ & $0.28 \pm 0.006$ & 0.5 \\
Soleus muscle weight (g) & $0.084 \pm 0.002$ & $0.085 \pm 0.004$ & 0.9 \\
per 100 g IBW & & & \\
\hline
\end{tabular}

intake, as measured by CLAMS during the dietary intervention, was $248 \pm 10 \mathrm{kcal}$ in HFD rats and $218 \pm 12 \mathrm{kcal}$ in ND rats $(P=0.075)$.

Effect of chronic HFD on expression of genes involved in fat oxidation and mitochondrial biogenesis in the adipose tissue, liver and skeletal muscle

We examined mRNA expression of genes involved in fatty acid oxidation and mitochondrial biogenesis in retroperitoneal fat, epididymal fat, liver and soleus muscle. These analyses showed that, in HFD compared with ND rats, expression of the acyl-CoA dehydrogenase, long-chain ( $A c a d l$ ) gene, encoding an enzyme catalyzing the first step of fatty acid oxidation, was higher by 1.7 -fold $(P=0.008)$ in retroperitoneal fat and by 1.4 -fold $(P=0.003)$ in the liver, but it did not vary between the groups in epididymal fat (Supplementary Figure S1) and soleus muscle (Figure 2). Expression of $P g c-1 \alpha$, which encodes a transcription factor coordinating the expression of nuclear and mitochondrial genes involved in mitochondrial biogenesis, ${ }^{19}$ was also higher in HFD than ND rats but only in retroperitoneal fat (by 2.4-fold, $P=0.04$ ) and not in the liver or soleus muscle (Figure 2).

\section{Effect of chronic HFD on mitochondrial copy number in the} adipose tissue, liver and skeletal muscle

$P g c-1 \alpha$ expression is considered an indicator of mitochondrial biogenesis. ${ }^{19}$ On this basis, we examined mitochondrial DNA copy number, assessed as quantitative ratios of two mitochondrial genes (Cox1 and $C y t b)$ to a nuclear gene (18S). Consistent with our gene expression results, mtDNA copy number was significantly higher in HFD compared with ND rats in retroperitoneal fat $(\operatorname{Cox} 1, P=0.04$ and $C y t b, P=0.02$ ) but not in the liver or soleus muscle (Figure 3 ).

\section{Effect of chronic HFD on brown fat adipogenesis in WAT}

The increase in expression of $P g c-1 \alpha$ and mitochondrial copy number we observed in retroperitoneal fat of HFD rats suggested that brown fat may have emerged in this traditional WAT deposit in response to a chronic HFD. To confirm this possibility, we examined the cellular morphology of retroperitoneal fat with histology and the expression of Ucp1, a brown fat-defining protein, ${ }^{9}$ in this tissue with qRT-PCR, western blot analysis and immunohistochemistry. The classical histology revealed the presence of small multilocular cells dispersed in patches or as single cells among large unilocular white adipocytes in

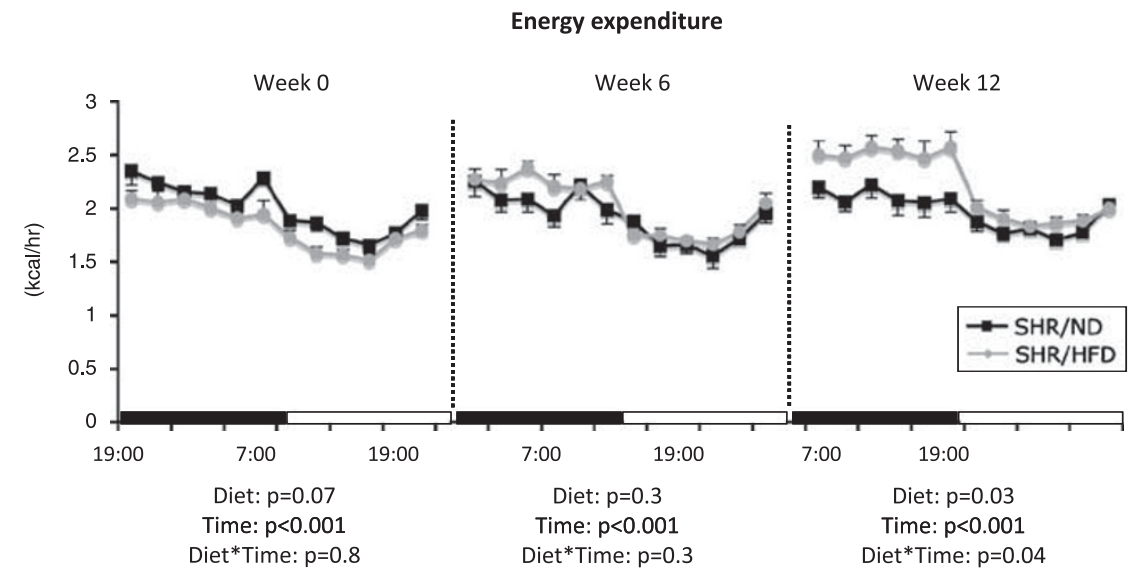

Figure 1 Effect of a 12-week high-fat diet (HFD) on energy expenditure. Energy expenditure (calculated from $\mathrm{O}_{2}$ consumption and $\mathrm{CO}_{2}$ production as heat production) was monitored with the Comprehensive Laboratory Animal Monitoring System (CLAMS) for at least two 24-hour periods, with the first one used for acclimatization to the system and the second for statistical analyses. The measurements were made prior to a 12-week dietary intervention (week 0) and at weeks 6 and 12 of the intervention. Means \pm s.e.m. of $2 \mathrm{~h}$ averages of these measurements are presented for ND ( $n=6)$ and HFD ( $n=8)$ rats. Data were analyzed with two-way analysis of variance with diet (HFD vs. ND) and time (light and dark) as main factors. 

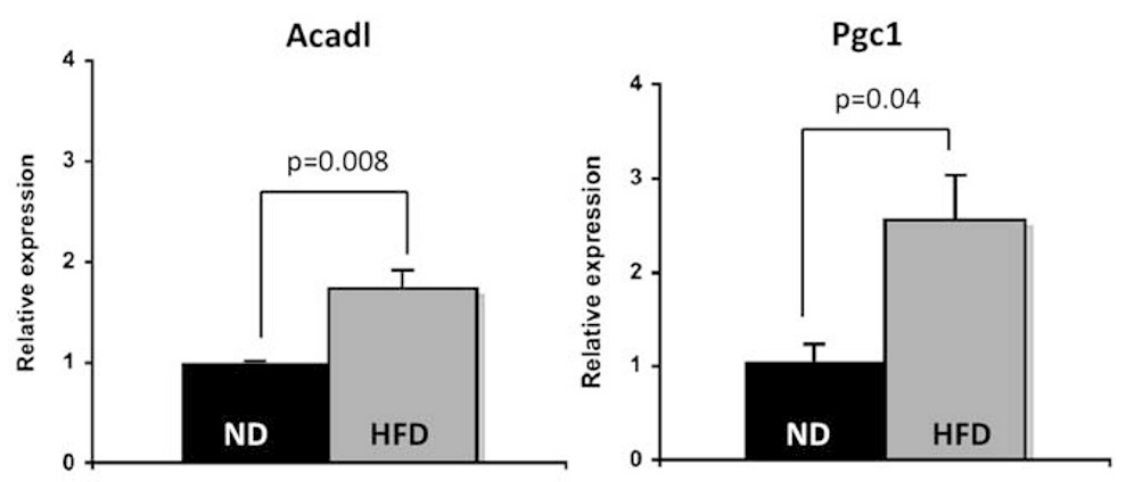

b

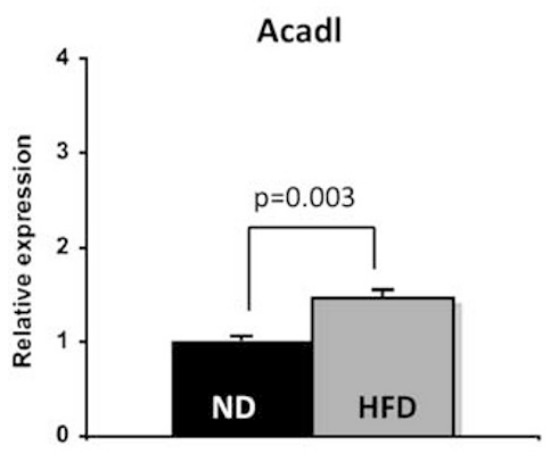

Liver

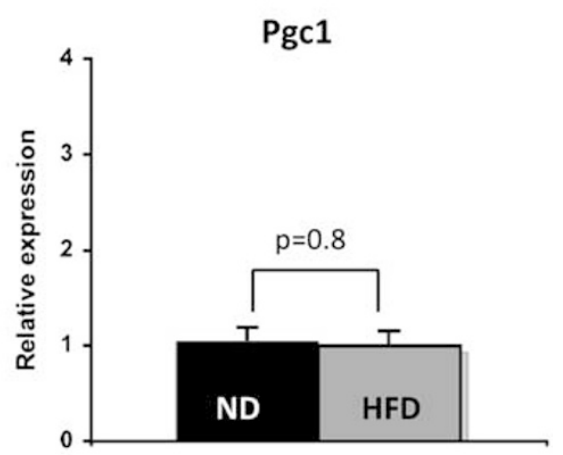

C

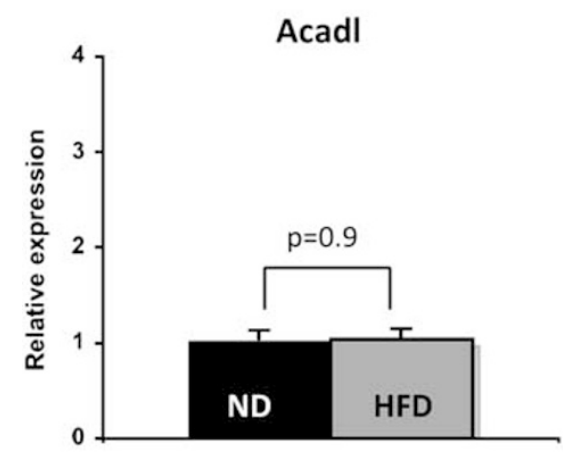

Soleus muscle

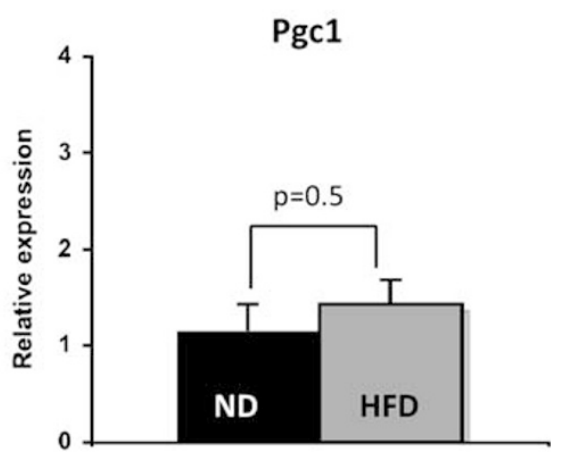

Figure 2 Effect of a 12-week high-fat diet (HFD) on mRNA expression of genes involved in fatty acid oxidation and mitochondrial biogenesis in retroperitoneal fat (a), liver (b) and soleus muscle (c). Expression of the long-chain acyl-CoA dehydrogenase (Acadl) gene, encoding an enzyme catalyzing the first step of fatty acid oxidation, and of the peroxisome proliferator-activated receptor- $\gamma$ coactivator- $1 \alpha$ (Pgc- $1 \alpha$ ) gene, which encodes a transcription factor coordinating the expression of nuclear and mitochondrial genes involved in mitochondrial biogenesis, were examined with quantitative RT-PCR. Means \pm s.e.m. are presented for ND $(n=5-6)$ and HFD $(n=8)$ rats. Data were analyzed with Student's $t$-test.

HFD but not in ND rats (Figure 4). The result of qRT-PCR showed that mRNA expression of Ucp1 in retroperitoneal fat was upregulated by $>12$-fold in HFD vs. ND rats $(P<0.05$, Figure 4$)$. Western blot analysis demonstrated that protein expression of UCP1 is well detectable in HFD but not in ND rats (Supplementary Figure S2). Finally, immunohistochemistry demonstrated the presence of the UCP1 protein in areas of retroperitoneal fat that contained the small multilocular cells described above (Figure 4). Collectively, these results suggest that, in SHR, a chronic HFD leads to the emergence of brown-like adipocytes in this traditional WAT.

Apart from the above studies of retroperitoneal fat, we examined mRNA expression of Ucp1 in epididymal fat, liver and skeletal muscle in HFD rats using qRT-PCR. In all of these tissues, mRNA expression of Ucp1 was not detectable (Supplementary Figure S3).

\section{Effect of chronic HFD on expression of genes involved in brown fat} adipogenesis

To determine the underlying mechanisms of diet-induced emergence of brown fat in retroperitoneal fat, we examined mRNA expression of candidate genes likely involved in this process. These included a gene encoding the $\beta 3$-adrenergic receptor ( $A d r b 3$ ), which has been shown to stimulate brown fat adipogenesis in rodents, ${ }^{20,39}$ and genes encoding several key transcription factors and signaling molecules implicated in the control of brown-adipocyte differentiation. ${ }^{16,17}$ The latter 
a

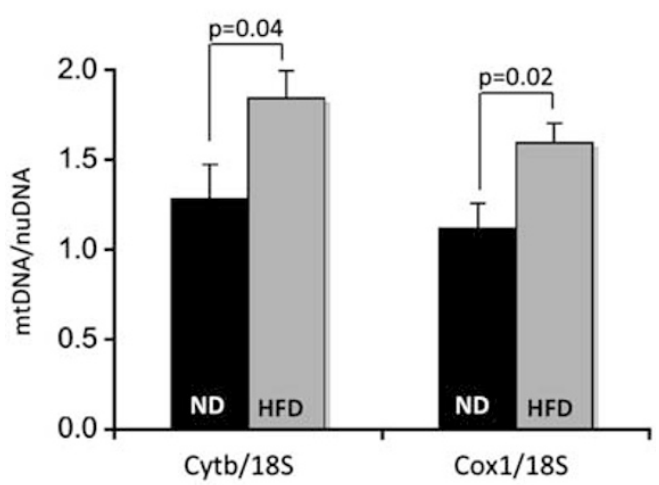

b

Liver

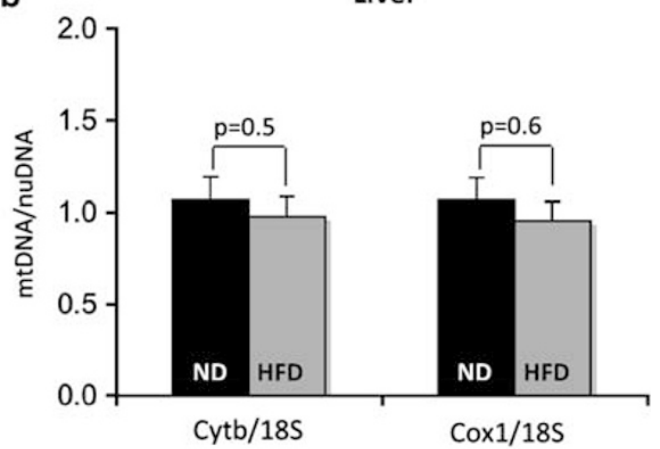

c

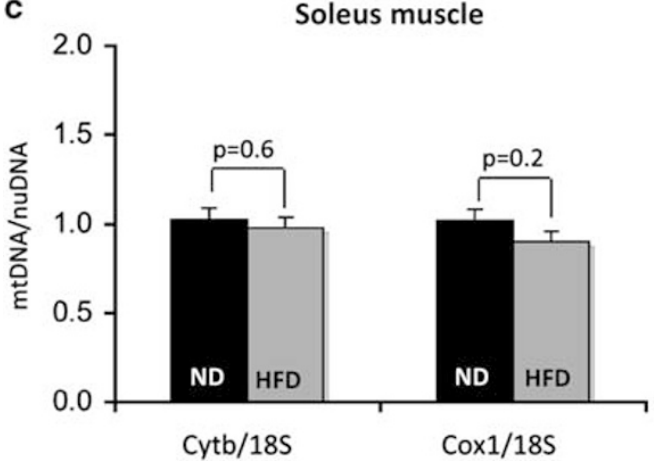

Figure 3 Effect of a 12-week high-fat diet (HFD) on mitochondrial copy number in retroperitoneal fat (a), liver (b) and soleus muscle (c). Mitochondrial DNA copy number was assessed as the quantitative ratios of mitochondrial cytochrome b (Cytb) and cytochrome c oxidase I (Cox1) genes to the nuclear $18 \mathrm{~S}$ ribosomal RNA gene (18S). Means \pm s.e.m. are presented for ND $(n=5)$ and HFD $(n=8)$ rats. Data were analyzed with Student's $t$-test.

included the PR domain containing 16 (Prdm16), nuclear respiratory factor 1 (Nrf1), mitochondrial transcription factor A (Tfam) and mitogen-activated protein kinase 14 (Mapk14) genes. The results showed that mRNA expression of $A d r b 3$ and $P r d m 16$ was significantly higher in HFD than ND rats (Figure 5, $P=0.009$ and 0.008 , respectively), suggesting their involvement in diet-induced emergence of brown fat in WAT observed in this study, whereas Nrf1, Tfam and Mapk14 expression was not significantly different between the two dietary groups (Figure 5). In addition, it has been suggested that a molecular signature of some precursors of brown adipocytes is the expression of muscle developmental gene, myogenic factor 5
(Myf5). ${ }^{15,16}$ In this study, we did not detect mRNA of this gene in retroperitoneal fat in either ND or HFD rats (Supplementary Figure S4).

\section{DISCUSSION}

The results of this study suggest that, in response to a chronic HFD, SHR increased whole-body energy expenditure. This was accompanied by enhanced expression of genes involved in fat oxidation, mitochondrial biogenesis and brown fat adipogenesis and by augmented mitochondrial mass in WAT but not in the liver or skeletal muscle. These results taken together with the appearance of multilocular cells staining positively for UCP1 within WAT suggest that a chronic HFD induces the emergence of brown fat in WAT of SHR rats. This increase in brown fat may increase energy utilization via energy dissipation in the form of heat and, thus, contribute to the observed increase in whole-body energy expenditure.

To our knowledge, this is the first study to demonstrate that a chronic HFD induces emergence of brown-like adipocytes in WAT and enhances whole-body energy expenditure. Previous studies found brown fat emergence in WAT coupled with enhanced whole-body energy expenditure, but these studies used non-dietary manipulations, including chronic exposure to cold, treatment with $\beta 3$-adrenergic receptor agonists and forced WAT overexpression of key molecules of brown fat adipogenesis/function, such as PGC- $1 \alpha$, UCP1 or PRDM16. ${ }^{12,14,18,20,39-42}$

Brown fat adipogenesis has recently gained the interest of many research groups, as compelling evidence has been provided that brown fat exists not only in human neonates, as thought originally, but also in human adults where it likely protects against obesity, ${ }^{2-8}$ through its superior capacity for burning fat (both stored and eaten) and energy dissipation. ${ }^{9,43}$ Substantial progress in our understanding of brown fat adipogenesis has been made recently (Seale et al. ${ }^{43}$ ). We know that a complex network of transcription factors orchestrate the development of brown adipocyte islands in WAT and that this network may not be the same in classical brown fat depots, such as interscapular brown fat. ${ }^{43}$ In case of the latter, precursors of brown adipocytes are of the skeletal muscle lineage and are characterized by the expression of muscle developmental gene Myf5. ${ }^{15,16}$ Their fate as to whether they develop into muscle or brown fat cells is determined to a great degree by the transcription factor PRDM16, which activates a complete brown fat-differentiation program in these precursor cells. ${ }^{16}$ In the case of brown fat islands present in WAT, it is still debated whether they develop from specific precursors present in WAT or by a true transformation of white to brown adipocytes. ${ }^{44,45}$ Whichever is the case, these cells apparently never express Myf5. ${ }^{16}$ Consistent with these findings, we did not detect expression of $M y f 5$ in retroperitoneal fat of either ND or HFD rats. Finally, we observed a significant upregulation of Prdm16 in this tissue in HFD compared with ND rats; this is in agreement with a recent study demonstrating that PRDM16 overexpression in WAT results in emergence of brown-like adipocytes in this tissue. ${ }^{18}$

In this study, we observed that mRNA expression of Adrb3 in retroperitoneal fat was significantly higher in HFD than ND rats. Upregulation of $A d r b 3$ is consistent with previous research demonstrating that adrenergic stimulation ${ }^{8}$ via the $\beta_{3}$-adrenergic receptor has a key role in brown fat activation and subsequent energy dissipation, ${ }^{8}$ as well as emergence of brown fat in WAT. ${ }^{20,39,46}$ Further, islands of brown adipocytes in WAT are richly sympathetically innervated. ${ }^{6}$ The HFD-induced brown fat adipogenesis in WAT that we observed in this study may be because of strain-specific sensitivity to the diet perturbation. It has previously been shown that SHR compared with Wistar 
a Ucp1
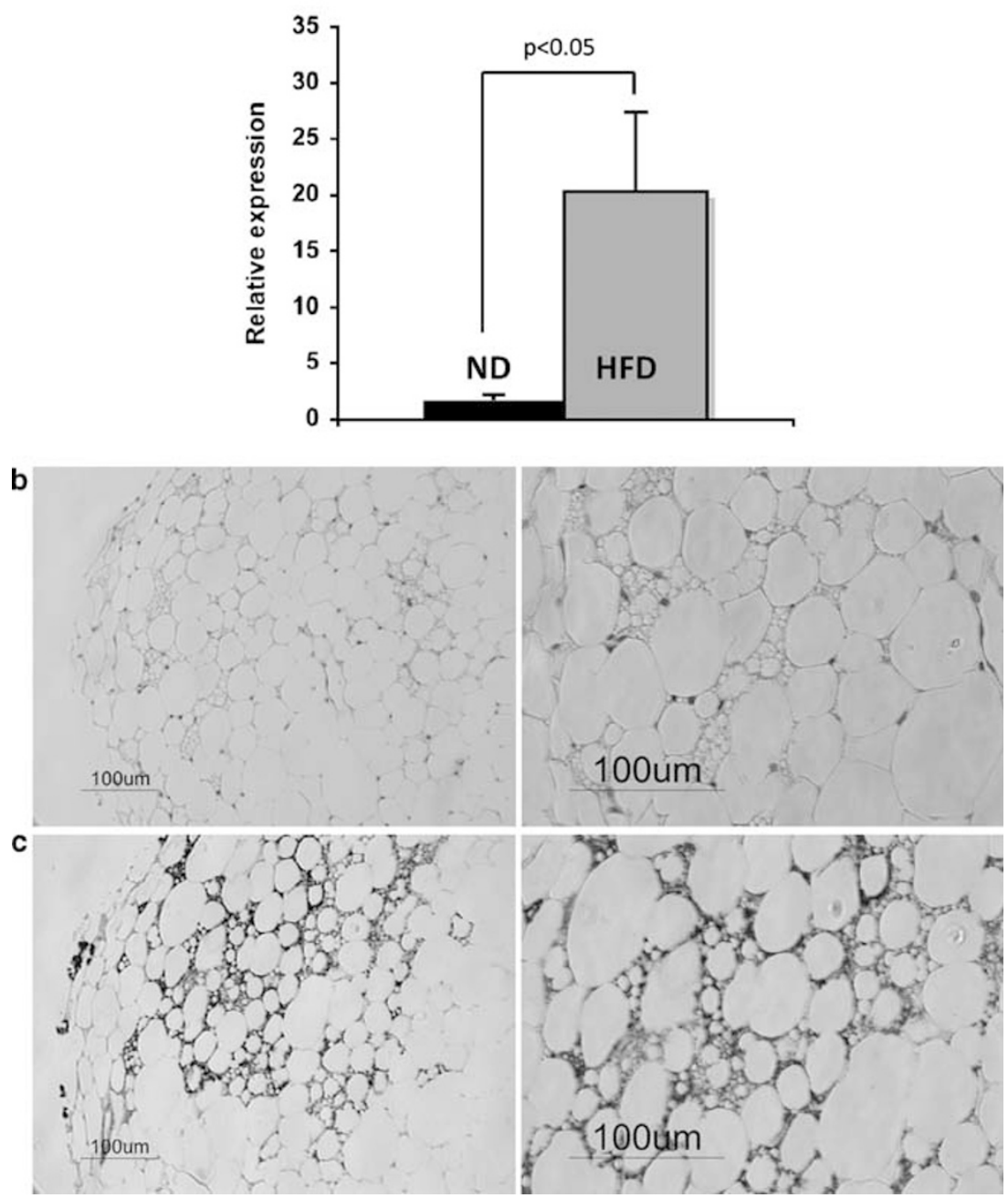

Figure 4 Effect of a 12-week high-fat diet (HFD) on brown fat emergence in retroperitoneal fat. (a) Expression of Ucp1 was evaluated by quantitative RT-PCR. Means \pm s.e.m. are presented for ND $(n=5)$ and HFD $(n=8)$ rats. Data were analyzed with a non-parametric Wilcoxon's test. (b) Hematoxylinphloxin-saffron staining of $5-\mu \mathrm{m}$ sections of retroperitoneal fat demonstrating characteristic morphological features of brown fat, namely, multilocular brown adipocytes dispersed in patches or as individual cells among unilocular white adipocytes. Representative sections from a HFD rat are shown. Light microscopy with $\times 20$ (left) and $\times 40$ (right) magnification was used. (c) Immunohistochemistry of $5-\mu \mathrm{m}$ sections of retroperitoneal fat demonstrating UCP1protein immuno-positivity in the regions of brown fat defined morphologically. Representative sections from a HFD rat are presented. Light microscopy with $\times 20$ (left) and $\times 40$ (right) magnification was used. Negative controls were performed with the same protocol, with the primary antibody being omitted (Supplementary Figure S5). A full color version of this figure is available at the Hypertension Research journal online.

Kyoto rats, for example, demonstrate higher interstitial norepinephrine release in WAT. ${ }^{26,27}$ In WAT of SHR, adrenergic nerve fibers are abundantly distributed not only around vessels but also directly on parenchymal cells, including adipocytes. ${ }^{26}$

In addition, SHR are characterized by a deletion mutation of $C d 36,{ }^{47,48}$ which is a fatty acid transporter that mediates fatty acids uptake by adipocytes (and other cells) and is involved in cold-induced brown fat thermogenesis. ${ }^{49}$ Because of the deletion mutation, Cd36 is undetectable in SHR adipocyte plasma membrane. ${ }^{47,48}$ Whether this genetic alteration has a role in the observed HFD-induced brown-fat emergence in WAT requires further studies, however.

In this study, diet-induced emergence of brown fat in WAT was observed in the retroperitoneal fat pads, but not in the epididymal fat pads. The reason for this fat-pad variation is not entirely clear, however, a likely explanation is that fat-pads differ in the density of sympathetic innervation ${ }^{50,51}$ and/or cell-autonomous inducibility of molecular pathways of brown fat adipogenesis. ${ }^{18}$ Supporting the former, it has been shown that the number of sympathetic nerve fibers correlates positively with the density of brown adipocytes in $\mathrm{WAT}^{52}$ and that norepinephrine concentration varies among fat pads, being higher, for example, in retroperitoneal than epididymal fat pads in Siberian hamsters. ${ }^{50,51}$ With respect to cell-autonomous inducibility of molecular pathways of brown fat adipogenesis, it has been shown that mRNA expression of Prdm16 is higher in inguinal than epididymal fat pads in B6 mice, and that adipose tissue overexpression of Prdm16 on this genetic background results in emergence of brown-like adipocytes in inguinal but not in epididymal fat pads. ${ }^{18}$ The retroperitoneal and inguinal fat pads (but not epididymal fat pads to our knowledge) showed emergence of brown fat (in response to cold or $\beta_{3}$-stimulation) in several previous studies. $^{22,45,53}$ Some of these studies indicated that the capacity for brown fat adipogenesis in WAT depends largely on genetic 

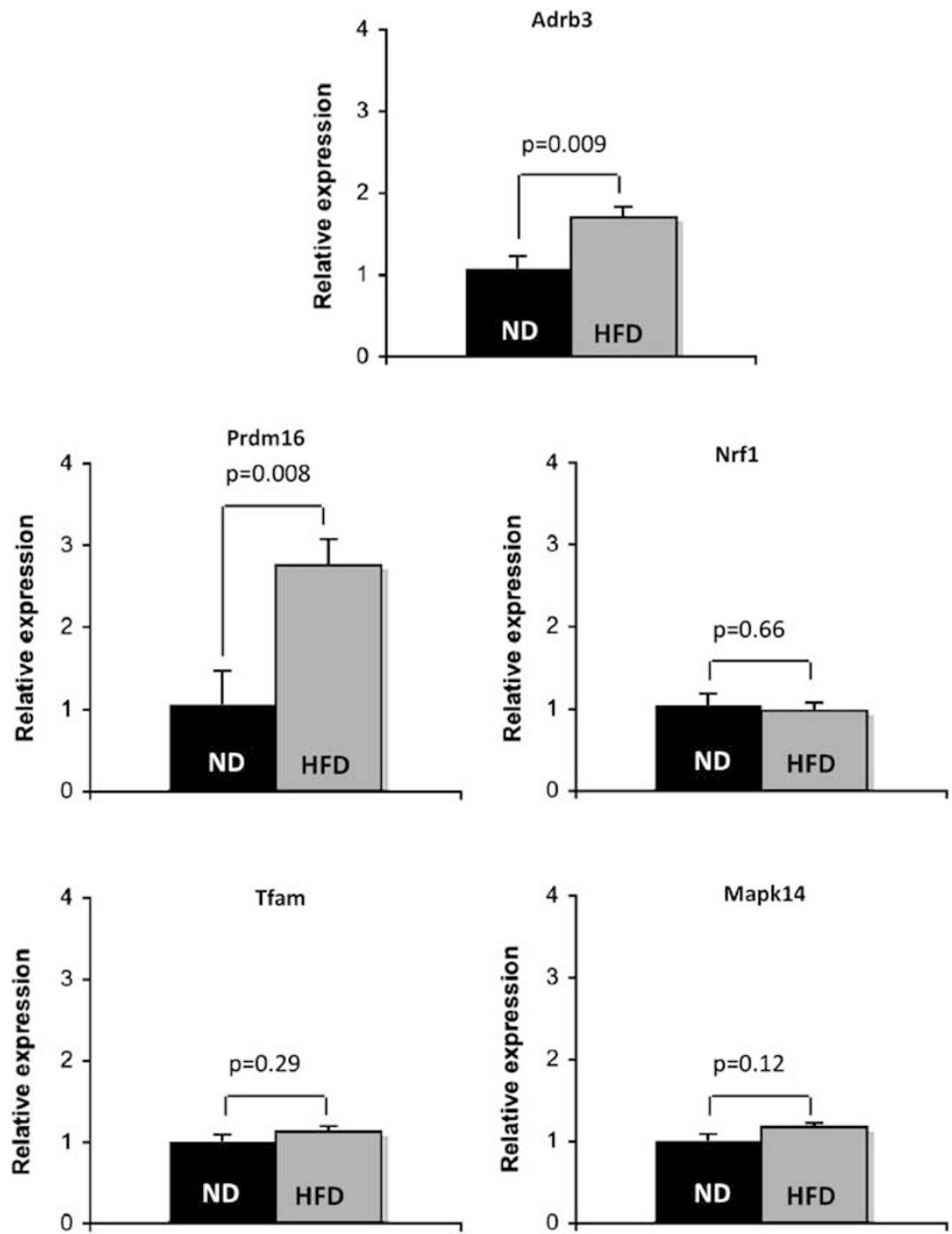

Figure 5 Effect of a 12-week high-fat diet (HFD) on mRNA expression of genes potentially involved in brown fat emergence in retroperitoneal fat. Expression of genes encoding the $\beta 3$-adrenergic receptor (Adrb3) and several key transcription factors and signaling molecules implicated in the control of brown adipocyte differentiation, namely the PR domain containing 16 (Prdm16), nuclear respiratory factor 1 (Nrf1), mitochondrial transcription factor A (Tfam) and mitogen-activated protein kinase 14 (Mapk14) genes, was examined with quantitative RT-PCR. Means \pm s.e.m. are presented for ND ( $n=5)$ and HFD ( $n=8$ ) rats. Data were analyzed with Student's $t$-test.

makeup of studied animal models. ${ }^{22,53}$ To understand which specific genes and whether they primarily control fat pad-specific cell-autonomous or whole-tissue properties requires further research, however. Additional studies are also needed to examine whether similar brown fat adipogenesis occurs in other fat depots, including subcutaneous white fat and interscapular brown fat.

The results of this study suggest that the SHR may be a useful animal model of the emergence of brown fat in WAT induced by a chronic HFD. As excess fat-intake is a major contributor to the current epidemic of obesity, and brown fat emergence in WAT may be a new biological pathway protecting an individual from dietary obesity, the SHR may be an important model to reveal novel mechanisms of resistance to environmental obesity. This may be particularly significant, as metabolically active brown fat, including that in WAT, exists in adult humans, ${ }^{2-7}$ but the mechanisms of its emergence are still not clear.

\section{CONFLICT OF INTEREST}

The authors declare no conflict of interest.

\section{ACKNOWLEDGEMENTS}

We thank Dr Tomas Paus for his helpful comments on the manuscript. The Canadian Institutes of Health Research (MOP-37915) and the University of Nottingham, Nottingham, UK supported this study.

1 Isomaa B. A major health hazard: the metabolic syndrome. Life Sci 2003; 73 : 2395-2411.

2 Nedergaard J, Bengtsson T, Cannon B. Unexpected evidence for active brown adipose tissue in adult humans. Am J Physiol Endocrinol Metab 2007; 293: E444-E452.

3 van Marken Lichtenbelt WD, Vanhommerig JW, Smulders NM, Drossaerts JM, Kemerink GJ, Bouvy ND, Schrauwen P, Teule GJ. Cold-activated brown adipose tissue in healthy men. N Engl J Med 2009; 360: 1500-1508. 
4 Virtanen KA, Lidell ME, Orava J, Heglind M, Westergren R, Niemi T, Taittonen M, Laine J, Savisto NJ, Enerback S, Nuutila P. Functional brown adipose tissue in healthy adults. N Engl J Med 2009; 360: 1518-1525.

5 Cypess AM, Lehman S, Williams G, Tal I, Rodman D, Goldfine AB, Kuo FC, Palmer EL, Tseng YH, Doria A, Kolodny GM, Kahn CR. Identification and importance of brown adipose tissue in adult humans. N Engl J Med 2009; 360: 1509-1517.

6 Zingaretti MC, Crosta F, Vitali A, Guerrieri M, Frontini A, Cannon B, Nedergaard J, Cinti S. The presence of UCP1 demonstrates that metabolically active adipose tissue in the neck of adult humans truly represents brown adipose tissue. FASEB J 2009; 23: 3113-3120.

7 Saito M, Okamatsu-Ogura Y, Matsushita M, Watanabe K, Yoneshiro T, Nio-Kobayashi J, Iwanaga T, Miyagawa M, Kameya T, Nakada K, Kawai Y, Tsujisaki M. High incidence of metabolically active brown adipose tissue in healthy adult humans: effects of cold exposure and adiposity. Diabetes 2009; 58: 1526-1531.

8 Cannon B, Nedergaard J. Metabolic consequences of the presence or absence of the thermogenic capacity of brown adipose tissue in mice (and probably in humans). Int J Obes (Lond) 2010; 34(Suppl 1): S7-S16.

9 Cannon B, Nedergaard J. Brown adipose tissue: function and physiological significance. Physiol Rev 2004; 84: 277-359.

10 Hull D. The structure and function of brown adipose tissue. Br Med Bull 1966; 22 : 92-96.

11 Echtay KS. Mitochondrial uncoupling proteins - what is their physiological role? Free Radic Biol Med 2007; 43: 1351-1371.

12 Cousin B, Cinti S, Morroni M, Raimbault S, Ricquier D, Penicaud L, Casteilla L. Occurrence of brown adipocytes in rat white adipose tissue: molecular and morphological characterization. J Cell Sci 1992; 103 (Pt 4): 931-942.

13 Cinti S. The adipose organ. Prostaglandins Leukot Essent Fatty Acids 2005; 73: 9-15.

14 Kopecky J, Clarke G, Enerback S, Spiegelman B, Kozak LP. Expression of the mitochondrial uncoupling protein gene from the aP2 gene promoter prevents genetic obesity. J Clin Invest 1995; 96: 2914-2923.

15 Timmons JA, Wennmalm K, Larsson O, Walden TB, Lassmann T, Petrovic N, Hamilton DL, Gimeno RE, Wahlestedt C, Baar K, Nedergaard J, Cannon B. Myogenic gene expression signature establishes that brown and white adipocytes originate from distinct cell lineages. Proc Natl Acad Sci USA 2007; 104: 4401-4406.

16 Seale P, Bjork B, Yang W, Kajimura S, Chin S, Kuang S, Scime A, Devarakonda S, Conroe HM, Erdjument-Bromage H, Tempst P, Rudnicki MA, Beier DR, Spiegelman BM. PRDM16 controls a brown fat/skeletal muscle switch. Nature 2008; 454: 961-967.

17 Tseng YH, Kokkotou E, Schulz TJ, Huang TL, Winnay JN, Taniguchi CM, Tran TT, Suzuki R, Espinoza DO, Yamamoto Y, Ahrens MJ, Dudley AT, Norris AW, Kulkarni RN, Kahn CR. New role of bone morphogenetic protein 7 in brown adipogenesis and energy expenditure. Nature 2008; 454: 1000-1004.

18 Seale P, Conroe HM, Estall J, Kajimura S, Frontini A, Ishibashi J, Cohen P, Cinti S, Spiegelman BM. Prdm16 determines the thermogenic program of subcutaneous white adipose tissue in mice. J Clin Invest 2011; 121: 96-105.

19 Puigserver P, Spiegelman BM. Peroxisome proliferator-activated receptor-gamma coactivator 1 alpha (PGC-1 alpha): transcriptional coactivator and metabolic regulator. Endocr Rev 2003; 24: 78-90.

20 Ghorbani M, Claus TH, Himms-Hagen J. Hypertrophy of brown adipocytes in brown and white adipose tissues and reversal of diet-induced obesity in rats treated with a beta3adrenoceptor agonist. Biochem Pharmacol 1997; 54: 121-131.

21 Vegiopoulos A, Muller-Decker K, Strzoda D, Schmitt I, Chichelnitskiy E, Ostertag A, Berriel Diaz M, Rozman J, Hrabe de Angelis M, Nusing RM, Meyer CW, Wahli W, Klingenspor M, Herzig S. Cyclooxygenase-2 controls energy homeostasis in mice by de novo recruitment of brown adipocytes. Science 2010; 328: 1158-1161.

22 Guerra C, Koza RA, Yamashita H, Walsh K, Kozak LP. Emergence of brown adipocytes in white fat in mice is under genetic control. Effects on body weight and adiposity. J Clin Invest 1998; 102: 412-420.

23 Schwartz JH, Young JB, Landsberg L. Effect of dietary fat on sympathetic nervous system activity in the rat. J Clin Invest 1983; 72: 361-370.

24 Okamoto K, Aoki K. Development of a strain of spontaneously hypertensive rats. Jpn Circ J 1963; 27: 282-293.

25 Patel KP, Kline RL, Mercer PF. Noradrenergic mechanisms in the brain and peripheral organs of normotensive and spontaneously hypertensive rats at various ages. Hypertension 1981; 3: 682-690.

26 Cabassi A, Vinci S, Cantoni AM, Quartieri F, Moschini L, Cavazzini S, Cavatorta A, Borghetti A. Sympathetic activation in adipose tissue and skeletal muscle of hypertensive rats. Hypertension 2002; 39: 656-661.

27 Cabassi A, Bergamaschi E, Mutti A, Franchini I, Borghetti A. Age-related changes in interstitial norepinephrine. A microdialysis study in spontaneously hypertensive rats. Am J Hypertens 1996; 9: 878-883.

28 Pausova Z, Sedova L, Berube J, Hamet P, Tremblay J, Dumont M, Gaudet D, Pravenec $M$, Kren V, Kunes J. Segment of rat chromosome 20 regulates diet-induced augmenta- tions in adiposity, glucose intolerance, and blood pressure. Hypertension 2003; 41: 1047-1055.

29 Bourdon C, Hojna S, Jordan M, Berube J, Kren V, Pravenec M, Liu P, Arab S, Pausova Z. Genetic locus on rat chromosome 20 regulates diet-induced adipocyte hypertrophy: a microarray gene expression study. Physiol Genomics 2009; 38: 63-72.

30 Knight SF, Quigley JE, Yuan J, Roy SS, Elmarakby A, Imig JD. Endothelial dysfunction and the development of renal injury in spontaneously hypertensive rats fed a high-fat diet. Hypertension 2008; 51: 352-359.

31 Rattigan S, Howe PR, Clark MG. The effect of a high-fat diet and sucrose drinking option on the development of obesity in spontaneously hypertensive rats. Br J Nutr 1986; 56: 73-80.

32 Contreras RJ, Williams VL. Dietary obesity and weight cycling: effects on blood pressure and heart rate in rats. Am J Physiol 1989; 256: R1209-R1219.

33 Zhang T, Reid K, Acuff CG, Jin CB, Rockhold RW. Cardiovascular and analgesic effects of a highly palatable diet in spontaneously hypertensive and Wistar-Kyoto rats. Pharmacol Biochem Behav 1994; 48: 57-61

34 McLean JA, Tobin G. Calorific equivalents. In: Tobin G (ed). Animal and Human Calorimetry. Cambridge University Press: Cambridge, 2008, pp 24-50.

35 McLean JA, Tobin G. Indirect calorimeters. In: Tobin G (ed). Animal and Human Calorimetry. Cambridge University Press: Cambridge, 2008, pp 50-120.

36 Pfaffl MW. A new mathematical model for relative quantification in real-time RT-PCR. Nucleic Acids Res 2001; 29: e45.

37 Pohjanvirta R, Niittynen M, Linden J, Boutros PC, Moffat ID, Okey AB. Evaluation of various housekeeping genes for their applicability for normalization of mRNA expression in dioxin-treated rats. Chem Biol Interact 2006; 160: 134-149.

38 Nicklas JA, Brooks EM, Hunter TC, Single R, Branda RF. Development of a quantitative PCR (TaqMan) assay for relative mitochondrial DNA copy number and the common mitochondrial DNA deletion in the rat. Environ Mol Mutagen 2004; 44: 313-320.

39 Collins S, Daniel KW, Petro AE, Surwit RS. Strain-specific response to beta 3-adrenergic receptor agonist treatment of diet-induced obesity in mice. Endocrinology 1997; 138: 405-413.

40 Young P, Arch JR, Ashwell M. Brown adipose tissue in the parametrial fat pad of the mouse. FEBS Lett 1984; 167: 10-14.

41 Puigserver P, Wu Z, Park CW, Graves R, Wright M, Spiegelman BM. A cold-inducible coactivator of nuclear receptors linked to adaptive thermogenesis. Cell 1998; 92: 829-839.

42 Tiraby C, Tavernier G, Lefort C, Larrouy D, Bouillaud F, Ricquier D, Langin D. Acquirement of brown fat cell features by human white adipocytes. $J$ Biol Chem 2003; 278: 33370-33376.

43 Seale P, Kajimura S, Spiegelman BM. Transcriptional control of brown adipocyte development and physiological function—of mice and men. Genes Dev 2009; 23: 788-797.

44 Cannon B, Nedergaard J. Developmental biology: neither fat nor flesh. Nature 2008; 454: 947-948.

45 Barbatelli G, Murano I, Madsen L, Hao Q, Jimenez M, Kristiansen K, Giacobino JP, De Matteis R, Cinti S. The emergence of cold-induced brown adipocytes in mouse white fat depots is determined predominantly by white to brown adipocyte transdifferentiation. Am J Physiol Endocrinol Metab 2010; 298: E1244-E1253.

46 Collins S, Yehuda-Shnaidman E, Wang H. Positive and negative control of Ucp1 gene transcription and the role of beta-adrenergic signaling networks. Int $\mathrm{J}$ Obes (Lond) 2010; 34(Suppl 1): S28-S33.

47 Aitman TJ, Glazier AM, Wallace CA, Cooper LD, Norsworthy PJ, Wahid FN, Al-Majali KM, Trembling PM, Mann CJ, Shoulders CC, Graf D, St Lezin E, Kurtz TW, Kren V, Pravenec M, Ibrahimi A, Abumrad NA, Stanton LW, Scott J. Identification of Cd36 (fat) as an insulin-resistance gene causing defective fatty acid and glucose metabolism in hypertensive rats. Nat Genet 1999; 21: 76-83.

48 Pravenec M, Landa V, Zidek V, Musilova A, Kren V, Kazdova L, Aitman TJ, Glazier AM, Ibrahimi A, Abumrad NA, Qi N, Wang JM, St Lezin EM, Kurtz TW. Transgenic rescue of defective $\mathrm{Cd} 36$ ameliorates insulin resistance in spontaneously hypertensive rats. Nat Genet 2001; 27: 156-158.

49 Bartelt A, Bruns OT, Reimer R, Hohenberg H, Ittrich H, Peldschus K, Kaul MG, Tromsdorf UI, Weller H, Waurisch C, Eychmuller A, Gordts PL, Rinninger F, Bruegelmann $\mathrm{K}$, Freund B, Nielsen P, Merkel M, Heeren J. Brown adipose tissue activity controls triglyceride clearance. Nat Med 2011; 17: 200-205.

50 Brito NA, Brito MN, Bartness TJ. Differential sympathetic drive to adipose tissues after food deprivation, cold exposure or glucoprivation. Am J Physiol Regul Integr Comp Physiol 2008; 294: R1445-R1452.

51 Bowers RR, Festuccia WT, Song CK, Shi H, Migliorini RH, Bartness TJ. Sympathetic innervation of white adipose tissue and its regulation of fat cell number. Am J Physiol Regul Integr Comp Physiol 2004; 286: R1167-R1175.

52 Murano I, Barbatelli G, Giordano A, Cinti S. Noradrenergic parenchymal nerve fiber branching after cold acclimatisation correlates with brown adipocyte density in mouse adipose organ. J Anat 2009; 214: 171-178.

53 Coulter AA, Bearden CM, Liu X, Koza RA, Kozak LP. Dietary fat interacts with QTLs controlling induction of Pgc-1 alpha and Ucp1 during conversion of white to brown fat. Physiol Genomics 2003; 14: 139-147.

Supplementary Information accompanies the paper on Hypertension Research website (http://www.nature.com/hr) 